\title{
An Unusual Prostate-Specific Antigen Decrease in an Advanced Castration-Resistant Prostate Cancer Patient with Intracerebral Hemorrhage Subsequently Treated with Luteinizing Hormone-Releasing Hormone Antagonist
}

\author{
Kouji Izumi Atsushi Mizokami Mikio Namiki \\ Department of Integrative Cancer Therapy and Urology, Kanazawa University Graduate \\ School of Medical Science, Kanazawa, Japan
}

\section{Key Words}

Prostate cancer · Cerebral bleeding · Luteinizing hormone-releasing hormone antagonist

\begin{abstract}
An unusual prostate-specific antigen (PSA) decrease in a Japanese patient with advanced castration-resistant prostate cancer (CRPC) treated with luteinizing hormone-releasing hormone (LH-RH) antagonist after cerebral bleeding is presented. There have been no previous reports that cerebral bleeding or trepanation/drainage of hematoma decreased PSA level, which would make this the first. The LH-RH antagonist may be only one reason for the PSA decrease. More cases need to be accumulated and further investigation is needed to clarify if intracerebral bleeding or an LH-RH antagonist can decrease PSA in such advanced CRPC cases.

(C) 2013 S. Karger AG, Basel
\end{abstract}

\section{Case Report}

We experienced an unusual prostate-specific antigen (PSA) decrease in a Japanese patient with advanced castration-resistant prostate cancer (CRPC). The 63-year-old patient had a long history of prostate cancer with a Gleason score of $9(5+4)$ and T3aN0M1b, and

Kouji Izumi, MD, PhD

Department of Integrative Cancer Therapy and Urology

Kanazawa University Graduate School of Medical Science

13-1 Takara-machi, Kanazawa, Ishikawa 920-8641 (Japan)

E-Mail azuizu2003@yahoo.co.jp 
had already undergone treatment with combined androgen blockade, ethinylestradiol, prednisolone, estramustine phosphate, zoledronic acid, tranilast, tegafur uracil, docetaxel and strontium. At the maximum level of PSA $(1,235 \mathrm{ng} / \mathrm{ml})$, intracerebral bleeding occurred and the patient was hospitalized (fig. 1). Initially, the bleeding seemed to not be severe, so conservative therapy was performed. However, the bleeding began to increase, so trepanation with drainage for cerebral hematoma was performed by neurosurgeons (fig. 1). The PSA level decreased slightly following drainage. Two weeks after drainage, we replaced the luteinizing hormone-releasing hormone (LH-RH) agonist with the LH-RH antagonist degarelix. Surprisingly, the PSA level began to decrease from $873 \mathrm{ng} / \mathrm{ml}$ at the time of the first degarelix injection, with a level of $540 \mathrm{ng} / \mathrm{ml}$ attained after 4 weeks. During hospitalization, the treatment for prostate cancer was not changed except for the LH-RH antagonist injection. Unfortunately, the patient's condition deteriorated again with intracerebral bleeding, mydriasis and loss of light reflex, and he died 58 days after hospitalization.

\section{Discussion}

To our knowledge, there have been no previous reports that cerebral bleeding or trepanation/drainage of hematoma cause a decrease in the level of PSA. However, various acute insults induce a decrease of sex steroids and gonadotropins [1]. Low testosterone and luteinizing hormone are commonly observed in men who suffer burns [2, 3]. Similarly, 39\% of hemorrhagic and ischemic stroke patients have been found to have hypogonadism with a low testosterone level [4]. Though it is likely that the intracerebral bleeding affected the PSA level in our case, the decrease may also have been a fluctuation; it is not clear if the testosterone level of this CRPC patient treated with combined androgen blockade could have been reduced more by the intracerebral bleeding. The LH-RH antagonist may have contributed to the $56 \%$ decrease in PSA, from 1,235 to $540 \mathrm{ng} / \mathrm{ml}$. Two previous studies indicated that switching from LH-RH agonist to LH-RH antagonist could decrease PSA levels in CRPC patients [5, 6]. Degarelix, which is a recently developed LH-RH antagonist, showed a significantly lower risk of PSA progression or death in a certain population when compared with the LH-RH agonist [7]. The difference in effect between LH-RH agonist and antagonist could be explained by (1) a loss of testosterone surge or a reduction of testosterone, (2) the suppression of follicle-stimulating hormone and (3) a direct effect of the LH-RH antagonist on the LH-RH receptors in the prostate cancer cells [2]. A previous study indicated the possibility of a slight change in testosterone level being a cause of PSA decrease [5]. However, PSA levels in these previous studies were 3-60 ng/ml upon commencement of LHRH antagonist administration [5, 6]. Our case showed a PSA level of $873 \mathrm{ng} / \mathrm{ml}$ when the LH$\mathrm{RH}$ antagonist treatment was started, which is the highest level reported to date. The PSA level decrease in this case may therefore have been caused not only by the testosterone level but other mechanisms as well. Unfortunately, we did not measure either testosterone or follicle-stimulating hormone because we did not expect such a decrease in the level of the PSA. Our case demonstrates the therapeutic potential of LH-RH antagonist to decrease the PSA level in advanced CRPC patients. However, a previous report indicated that switching from LH-RH agonist to antagonist decreased PSA levels in only 3 of 17 prostate cancer patients [5]. Although it is necessary to still investigate the application of switching from LHRH agonist to LH-RH antagonist because of not much evidence, patients who have already undergone all available treatments, as in this particular case, may be eligible candidates for this approach. 


\begin{tabular}{l|l}
\hline \multicolumn{2}{l}{ Case Rep Nephrol Urol 2013;3:136-138 } \\
\hline DOI: 10.1159/000357668 & $\begin{array}{l}\text { @ 2013 S. Karger AG, Basel } \\
\text { www.karger.com/cru }\end{array}$ \\
\hline
\end{tabular}

Izumi et al.: An Unusual PSA Decrease in an Advanced CRPC Patient with Intracerebral Hemorrhage Subsequently Treated with LH-RH Antagonist

\section{References}

1 Woolf PD, Hamill RW, McDonald JV, Lee LA, Kelly M: Transient hypogonadotropic hypogonadism caused by critical illness. J Clin Endocrinol Metab 1985;60:444-450.

-2 Vogel AV, Peake GT, Rada RT: Pituitary-testicular axis dysfunction in burned men. J Clin Endocrinol Metab 1985;60:658-665.

3 Rolih CA, Ober KP: The endocrine response to critical illness. Med Clin North Am 1995;79:211-224.

-4 Dimopoulou I, Kouyialis AT, Orfanos S, Armaganidis A, Tzanela M, Thalassinos N, et al: Endocrine alterations in critically ill patients with stroke during the early recovery period. Neurocrit Care 2005;3:224-229.

5 Masson-Lecomte A, Guy L, Pedron P, Bruyere F, Rouprêt M, Nsabimbona B, et al: A switch from GnRH agonist to $\mathrm{GnRH}$ antagonist in castration-resistant prostate cancer patients leads to a low response rate on PSA. World J Urol 2013;31:339-343.

6 Raddin RS, Walko CM, Whang YE: Response to degarelix after resistance to luteinizing hormone-releasing hormone agonist therapy for metastatic prostate cancer. Anticancer Drugs 2011;22:299-302.

7 Tombal B, Miller K, Boccon-Gibod L, Schröder F, Shore N, Crawford ED, et al: Additional analysis of the secondary end point of biochemical recurrence rate in a phase 3 trial (CS21) comparing degarelix $80 \mathrm{mg}$ versus leuprolide in prostate cancer patients segmented by baseline characteristics. Eur Urol 2010;57:836842.

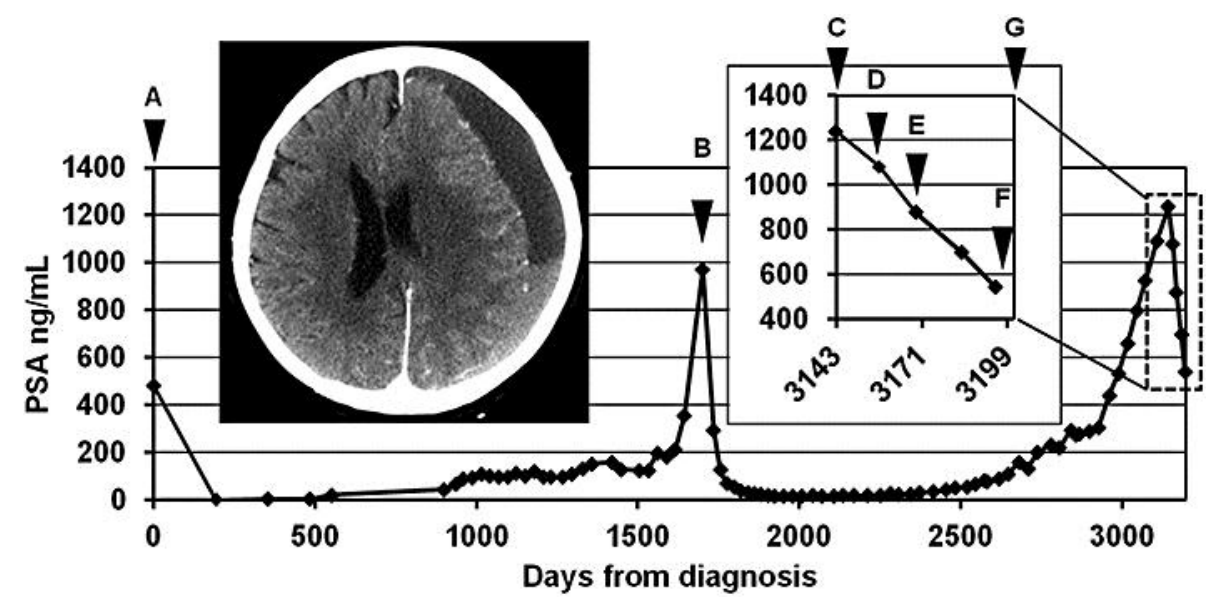

Fig. 1. The change in PSA levels is shown. The picture (left) shows cerebral bleeding before surgery. The arrowheads indicate specific events. A: combined androgen blockade is started, B: docetaxel administration is started, C: intracerebral bleeding occurs, D: trepanation is performed for cerebral hematoma, E: degarelix treatment is started, F: mydriasis and loss of light reflex are detected and G: the patient dies. 